Revista de Indias, 1996, vol. LVI, núm. 207

\title{
JULIO SANGUILY Y GARRITTE (1846-1906) \\ Y LOS ALZAMIENTOS DE FEBRERO DE 1895 EN EL OCCIDENTE DE CUBA
}

POR

\author{
MANUEL DE PAZ SÁNCHEZ
}

Universidad de La Laguna

El tema de los fracasados alzamientos insurreccionales del occidente cubano, en febrero de 1895, ha sido objeto de un largo debate historiográfico desde pocos años después de su acaecimiento. Diversos estudiosos cubanos, asi como los testimonios de los propios protagonistas de los hechos han contribuido, en numerosas ocasiones, a hacer aún más difícil la búsqueda de la verdad. Las razones de esta polémica están profundamente relacionadas con la hipotética relevancia de un levantamiento en toda regla a escasos kilómetros de la capital cubana, lo que, en teoría, hubiera acelerado el proceso emancipador y cambiado, de diversas maneras, el devenir de la contienda que se saldó con la pérdida de Cuba para España.

En nuestro trabajo sobre el bandolerismo cubano (1), insistimos en la importancia crucial de tales acontecimientos y, en esta ocasión, nos proponemos aportar nuevos datos sobre los hechos mencionados, particularmente sobre su aspecto más relevante: el papel jugado por el general cubano Julio Sanguily y Garritte, a quien se ha culpado del fracaso

\section{SIGLAS UTILIZADAS}

AGI: Archivo General de Indias, Sevilla.

AGM: Archivo General Militar, Segovia.

AHPM: Archivo Histórico Provincial, Matanzas.

ANC: Archivo Nacional de Cuba, La Habana.

(1) Manuel de PaZ-SÁnchez, José FernándeZ-Fernández y Nelson LóPEZNovegIL: El bandolerismo en Cuba (1800-1933). Presencia canaria y protesta rural. Prólogo de María Poumier, "Taller de Historia», Santa Cruz de Tenerife, 1993-1994, 2 vols., ver especialmente, tomo II, capítulos VII y VIII. 
del alzamiento occidental, particularmente en relación con la muerte del oficial insurrecto y antiguo bandolero social Manuel García Ponce.

\section{Julio SANGUily y GarRitte, «El GENERAL Maldito»}

El general Julio Sanguily y Garritte (1846-1906), había forjado su hoja de servicios durante la Guerra de los Diez Años. En 1871 fue hecho prisionero por las tropas españolas y, poco después, fue rescatado, en una acción épica, por el mayor general y jefe del Camagüey Ignacio Agramonte. Tras los acuerdos del Zanjón, Sanguily, que tuvo varios empleos y realizó otras actividades económicas, aparece como un elemento sospechoso ante las autoridades coloniales. Sus relaciones con el rebelde Carlos Agüero y, especialmente, con Manuel García Ponce; su forma de vida, bastante desordenada, y, sobre todo, sus contradicciones personales, le llevaron a ejercer un doble juego como agente de la Capitanía General y como "padrino" o protector de los bandoleros-insurrectos, en quienes tenía no sólo una baza para la empresa revolucionaria, sino, también, un medio para financiar su desproporcionado tren de vida. A Martí nunca le convenció, quizá porque conocía sus defectos (2).

Su imagen, empero, fue exaltada, en algún caso, con posterioridad a la Guerra de Independencia y su retrato fue llevado a la galería de patriotas del Ayuntamiento de La Habana. Tremols y Amat escribió que Julio Sanguily, «el Bayardo cubano, caballero sin tacha y sin miedo", fue reducido a prisión el mismo día 24 de febrero de 1895 y «encerrado en un calabozo de la fortaleza de la Cabaña, por creer el general Calleja que de irse Sanguily a la guerra que empezaba, sería difícil sofocarla. Para empeorar su situación y hacer inútiles las gestiones de la diplomacia americana que lo reclamaba como súbdito norteamericano que era, se le acusó de delitos comunes, infame calumnia que no prosperó» (3), por lo que fue puesto en libertad

(2) Como se deduce de numerosas cartas que pueden consultarse en los tomos III y IV de sus Obras Completas.

(3) En efecto, el 25 de junio de 1896 el cónsul general de los Estados Unidos en La Habana se interesó, ante la Capitanía General, por la «situa-

R. I., 1996, n. 207 
y se trasladó a Estados Unidos (4), de donde regresó al final de la contienda.

La ficha de "don Julio Sanguily» en los registros del Gabinete Particular contra el bandolerismo (1890-1892), organismo fundado por el capitán general Camilo García Polavieja y dirigido por el coronel García Aldave, así como numerosos testimonios que veremos a continuación, contribuyen a dibujar un perfil bastante singular de este personaje, colaborador de las autoridades coloniales desde, al menos, el mandato del general Salamanca y Negrete (1889), y, al mismo tiempo, "padrino» de Manuel García Ponce y de sus hombres (5), como ya apuntamos.

ción, salud y bienestar del ciudadano americano D. Julio Sanguily». A la misiva se acompañó un informe, en el que se hacía constar que Sanguily fue detenido en su casa de La Habana, siendo reducido a prisión «el primer día en que los rebeldes se alzaron en armas", y posteriormente se le sometió a juicio "por suponérsele que conspiraba para rebelarse». Más tarde, bajo el mandato de Martínez Campos, el anterior cónsul de los Estados Unidos, Mr. Williams, solicitó el indulto de Sanguily, basándose en que estaba comprendido en el bando dictado por Calleja por el que se indultaba «a todos los insurrectos que tuvieran las armas en la mano, con tal de que se presentaran ocho días después del bando», pues "si había indulto para los autores del delito consumado tenía que haberlo para los que, a lo más, lo habían intentado, sin llevarlo a efecto». Al parecer, Martínez Campos otorgó el visto bueno a la pronta salida de Sanguily con destino a los Estados Unidos, sin embargo, "después se dijo por algún enemigo de Julio Sanguily al General Campos que si cabía indulto por la causa política de conspiración, existía otra causa por delito común de secuestro, y que para ésta no había indulto. Ante esta consideración el General Campos retiró la oferta hecha sobre libertad de Sanguily a Mr. Williams. Ya no hay causa de secuestro, resuelta a favor de Sanguily por los Tribunales. Además: el indulto es asunto gubernativo, en el que no tienen intervención los Tribunales: puede hacerlo libremente el Gobernador General» (AGM! Legajo S-1401).

(4) A. Tremols y Amat: Los patriotas de la Galería del Ayuntamiento de La Habana. Imprenta «La Prueba», Habana, 1917, págs. 142-143.

(5) El texto de su ficha en los citados registros del Gabinete (AGI, Fondo Polavieja. Diversos 19) es el siguiente: «Dueño del ingenio 'Azopardo' en Unión de Reyes. Constantemente se halla en expediciones por las zonas donde merodean los bandidos. Se dice que ha realizado personalmente un atentado cerca de Unión de Reyes en compañía de otras siete personas de bastante significación en La Habana para alarmar a las Autoridades y al país y en especial al General Lachambre, hecho que probó el Cap. D. Eulogio Antón Rucandio. Va con frecuencia a la finca de D. Alfredo Hernández. Se vale de un hermano del negro Osma para dirigir su correspondencia a la partida de 
Una confidencia anónima que fue enviada, el 26 de agosto de 1890, al general Polavieja, aseguraba que tanto Julio Sanguily como Alfredo Hernández estaban señalados, en la provincia de Matanzas, entre los elementos que dirigían y secundaban "la acción de los bandidos»; que en un ingenio del segundo, ubicado en Sabanilla del Encomendador, se habían celebrado entrevistas con los malhechores, y que el capitán general debía informarse mediante personas de confianza, «sin oír mucho al elemento militar, porque se cuenta que también participa del botín con que contribuyen los del campo» (6).

Informaciones como la anterior, en efecto, hicieron meditar a Polavieja sobre la compleja trama que rodeaba al bandolerismo en Cuba y, en las semanas siguientes, sus sospechas fueron

Manuel García. Se tiene entendido que bajo la capa de gran confidente del E.S. Capitán General desde el difunto General Salamanca, frecuenta la finca 'Carmen de Hernández' y Bellocino, inmediatas a Ojo de Agua, por donde pulula un grupo de tres bandidos y que en Quivicán, en un ingenio de D. Mariano de la Torre, se entrevistó varias veces con Manuel García para dirigirlo e instruirlo, tomando él la parte que le corresponda del producto de los secuestros. [...]. En nota de encubridores de la Montaña, se dice que este Sr. es el director de todo con los bandidos, tiene un criado llamado Benito Rodríguez que es lo peor que hay".

(6) Anónimo a Polavieja, La Habana, 26 de agosto de 1890 (AGI. Diversos 19). Además el informe anónimo antes mencionado con relación a José María Aguirre, Manuel García y Montelongo (AGI. Diversos 19), contenía también los siguientes datos: "Sanguily va con mucha frecuencia a la finca de D. Alfredo Hernández que está cerca de la Unión. En la política que está metido de lleno el Alfredo, lo está Sanguily. Don Miguel Figueroa residente en Cárdenas, que cuando Maceo vivía en [el] $\mathrm{H}$ [otel] Inglaterra y venía Figueroa siempre estaba en el cuarto del primero secreteando, y un mulato que aparecía como sastre de Maceo, éste era el que iba como ayudante suyo. Cuando Figueroa estaba en Cárdenas con frecuencia se pasaban telegramas entre los dos, y un tal Manuel Suárez, brigadier que fue en la revolución [se refiere a Manuel Suárez Rosales, general canario en las guerras de emancipación de Cuba]. Estos todos conferenciaban con D. Hilario Cisneros, calle Peña Pobre, 25. Maceo era visita diaria de esa casa. D. Rodolfo Betancourt vive en el pueblo de Sabanilla del Encomendador; éste la misión que tiene allí como Jefe insurrecto es tener preparada la gente para el levantamiento; éste mismo está de completo acuerdo con los Jefes de los Palos, Vidal y Pérez y Acosta y todos obedecen a las oŕdenes con consigna de Gómez y Rovira, empleados de la Empresa Unida [de Ferrocarriles]. En los días que embarcaron a Maceo, se iba a reunirse a él un tal D. Anselmo Aragón que fue Jefe con el general Modesto Díaz en Oriente: conoce mucho todo aquel terreno, y creo hace poco hizo una excursión por allí».

R. I., 1996, n.o 207 
confirmadas por diversos conductos. El 2 de octubre, por ejemplo, el activo teniente Jerónimo Cuvertoret, en carta a José Schmid -segundo responsable del Gabinete Particular-, llamaba la atención sobre la conveniencia de "apretar el tornillo» a ciertos personajes civiles como Vicente Gutiérrez, alcalde de la Bermeja, y al alcalde de barrio de Los Palos, que conocían, en profundidad, «la vida y milagros de todos los vecinos». Cuvertoret, que subrayaba la necesidad de acabar con la red de solidaridades tejida en apoyo de los insumisos, apuntaba que, el último de los citados, podría aportar información valiosa sobre el señor Cuervo, ex-alcalde de Nueva Paz, y «también sabe algo de Sanguily que, según me dice dicho señor, tomó don Julio una cantidad por cuenta de la gente (7) en la tienda grande de Sabanilla, y hoy más que nunca está desplegando gran actividad y ejerce mucha presión sobre los hombres buenos que viven en el campo, haciéndoles creer que los muchachos (8) no son bandoleros sino los salvadores de la independencia» (9).

La policía de La Habana descubrió que, aparte de su casa de la calle Falgueras, donde realizaba una intensa vida social, Julio Sanguily tenía alquilada otra vivienda en Vista Hermosa, esquina a Lombillo, que era ocupada por el estudiante Antonio Cisneros, "el que con mucha frecuencia sale al campo, unas veces solo y otras con Sanguily» (10), aunque el dispositivo de vigilancia establecido no parece que, en definitiva, arrojara resultados destacables.

Paralelamente, el 26 de noviembre, según comunicó el celador Arredondo, Sanguily pasó por la estación de Nueva Paz, con objeto de "conferenciar con el bandido Andrés Santana, en el punto nombrado la Montaña, sin poderme enterar a qué se refirió dicha conferencia» (11).

(7) Con esta expresión, «la gente», se refería en realidad a los propios bandidos.

(8) También fue muy común designar, en la abundantísima documentación disponible, a los bandidos como «los muchachos». $\operatorname{sos} 16)$.

(9) Cuvertoret a J. Schmid, Palos, 2 de octubre de 1890 (AGI. Diver$\operatorname{sos} 19)$.

(10) Informes policiales del 5, 18 y 29 de noviembre de 1890 (AGI. Diver-

(11) Juan de Arredondo a García Aldave, Nueva Paz, 26 de noviembre de 1890 (AGI. Diversos 16). 
Las autoridades coloniales, en efecto, eran conscientes del riesgo que entrañaba el empleo de cierto tipo de colaboradores, pero se trataba de una vieja costumbre policial. Como afirmó García Aldave en diciembre, "nunca he confiado en Sanguily y en ningún otro, teniendo incluso Lavín atrevimiento proponer embarque, avistándose cuando quieren con jefes para esto y no para entregarlos» (12).

Para más abundamiento, una nota de mediados de enero de 1891 confirmaba los extraños manejos del general Sanguily. El día 13 había llegado al ingenio demolido "Concepción», propiedad de los Aldama y situado en Sabanilla, acompañado por Benito Rodríguez y por otro criado de su confianza. Según el informante, "desde esa fecha han recorrido varias fincas con el fin de recaudar (según noticias confidenciales), las cuotas que la partida de Manuel García tiene señaladas a las mismas». Además, resultaban sospechosas las visitas a la zona del médico Francisco Cabré, que no tenía clientes en la comarca y, asimismo, la amistad de Sanguily con el administrador de Correos, Pedro Sánchez, «dando éste a aquél en sus conversaciones íntimas el tratamiento de 'mi general'» (13).

Sanguily, empero, podía resultar un sospechoso útil, pese a la evidente necesidad de presionarlo, continuamente, para que pagase con hechos y no con palabras los favores y la confianza del alto mando colonial. El día 26 de enero, en respuesta a una carta de José Schmid, el general insurrecto reaccionó ante la presión del Gabinete y vindicó su dignidad como supuesto agente de la represión. "Ỵo no soy caviloso, yo juzgo por lo que leo. Nadie tiene más deseo que yo de acabar y que todos queden complacidos. Mejor que yo no lo hará nadie. Vd. mismo me ha recomendado que me situara en este punto, lejos de los movimientos de la tropa. Así es que tengo que andar mucho y que, como las operaciones son activas, se me hace difícil conse-

(12) Copia de telegrama de García Aldave, Aguacate, 17 de diciembre de 1890 (AGI. Diversos 18). Lavín era el alcalde de Nueva Paz, colaborador de las fuerzas policiales, aunque mantenía buenas relaciones con ciertos bandidos.

(13) Nota s.f. en AGI. Diversos 18. Se añade que "hace tiempo se le cayó en un descuido a Sanguily, en casa de don Narciso Piqué del comercio de Sabanillas, una relación con los nombres de casi todos los dueños de fincas con cantidades al margen...».

R. I., 1996, n. 207 
guir mi objeto. Sólo me falta ver al hombre (14) que espero de un momento a otro suceda, pues ya sé que tiene aviso. Ojalá fuera hoy mismo, pues deseo acabar. Yo no me distraigo mi tiempo en nada. Sólo me ocupo de eso. Asi es que si no salgo adelante pronto, culpa mía no es» (15).

Dos días más tarde, Sanguily volvía a escribir a su enlace. «Espero tener mañana temprano noticias de su amigo (16). En ese caso veré de verlo cuanto antes y arreglar algo. Bien poco me ha ayudado $\mathrm{Vd}$. porque no me ha indicado la zona donde andaba» (17). Sin embargo, a pesar de sus protestas y de su supuesta dedicación a la tarea represiva, el inefable general insurrecto no parece que, en el fondo, estuviera dispuesto a colaborar seriamente.

El 12 de febrero de 1891, el teniente coronel Gillermo Tort, otro destacado responsable de la represión del bandolerismo, informaba a García Aldave que uno de sus confidentes le había traído noticias de que, el día anterior, "se encontraba Manuel García por la Lima, Ingenio en el límite de Matanzas; que sus correrías son por la Margarita hasta los Tanques de Lavín; que en la montaña de Nueva Paz es donde está parando más y que en Palos tiene un espía muy activo llamado José de la Cruz Cabrera (18), con quien se entrevista con mucha frecuencia». Además, Tort había sabido por otra fuente "que Sanguily ha estado estos días haciendo una propaganda grandísima por Bermeja y Cabezas, excitando los ánimos de los campesinos para que protejan con todas sus fuerzas a los bandoleros echando pestes contra el Gobierno, tomando por pretexto lo hecho por Montelongos y Riveros y como este Sr. me inspira tan poca confianza, he mandado con licencia por tres

(14) Se refiere al bandido-insurrecto Manuel García Ponce.

(15) Sanguily a J. Schmid, Ing. "Concepción», 26 de enero de 1891 (AGI. Diversos 18). Subrayado en el original.

(16) Manuel García Ponce.

(17) Sanguily a J. Schmid, Ing. "Concepción», 28 de enero de 1891 (AGI. Diversos 18). Subrayado en el original.

(18) La ficha de José de la Cruz Cabrera en los registros del Gabinete Particular (AGI. Diversos 19), tiene la siguiente anotación: "Vive en el cuartón del Águila entre Nueva Paz y Bermeja, sirve de intermediario a D. Julio Sanguily para ponerlo en relación con los bandidos, dirige las fechorías y facilita armas, ropas y comestibles». 
o cuatro días a Bermeja al sargento de San Felipe que tiene allí novia y muchos conocimientos, para que con astucia y sagacidad, que las tiene, indague y se entere bien de todo para poder estar al corriente» (19).

Sin embargo, Sanguily continuó en activo. El 24 de abril se permitió, incluso, pedirle a García Aldave, a quien confiesa conocer "de hace poco, pero hay hombres como Vd., que cuando se ofrecen es de corazón", que revocara la orden de traslado a Santiago de Cuba del teniente Calvet, destinado en Alfonso XII (20). Además, a principios de junio, firmó un aviso con su nombre de guerra para las autoridades coloniales, Pancho (21).

Ante la carencia de resultados prácticos, debido a la parquedad de los informes de Sanguily o a la ineficacia de su utilización como señuelo, el Gabinete decidió que otro de sus agentes, Antonio Jiménez Barreto, le siguiera los pasos. En carta del 18 de julio, manifestaba éste último el rumor existente de que "con el tal hombre comparten algunos bandidos sus ganancias» $\mathrm{y}$, aunque la redacción de su epístola es confusa, parece deducirse que Jiménez Barreto no veía clara la labor represiva de Sanguily, "por aquello de que nunca un minero desea ver acabarse su filón»(22). Además, poco después, el agente confesó sin titubeos: "ese maldito cojo, dechado de pillerías, no me inspira confianza...», pues demostraba una incuestionable pasividad en la persecución de los bandidos y, por si fuera poco, explotaba «su generalato entre la gente rústica de la localidad», hasta el punto de apropiarse de algún caballo. "A todos choca y nadie se explica el por qué de su permanencia en el campo, de ahí las mil conjeturas, infaman-

(19) Tort a García Aldave, Güines, 12 de febrero de 1891 (AGI. Diversos 19). La referencia a los hermanos y bandidos de la partida de Manuel García Ponce, Montelongos y Riveros, alude al asesinato de éstos'-unas semanas antes-, en la propia bahía de La Habana, cuando, supuestamente, se proponían embarcar al exterior con la aquiescencia de las autoridades.

(20) Sanguily a García Aldave, Ing. "Concepción», 24 de abril de 1891 (AGI. Diversos 18).

(21) Comunicación de Sanguily, Ing. "Concepción», 7 de junio de 1891 (AGI. Diversos 18). "Deseo ver a V. para un asunto de importancia, el martes, a las ocho de la noche, en casa del coronel. Llevaré un amigo. Avísele al Coronel».

(22) Jiménez Barreto a García Aldave, Sabanilla, 18 de julio de 1891 (A.GI. Diversos 17).

\section{R. I., 1996, n.o 207}


tes algunas. Una persona distinguida me asegura que es amoroso el arcano, y al conocer a la dama volví a hundirme en el misterio, que no hay encantos para el tal sacrificio» (23).

¿Por qué, pues, las autoridades coloniales continuaron confiando en Julio Sanguily? Como hemos referido en otro lugar (24), a lo largo de 1891 se produjeron las muertes de varios insumisos de renombre, en las que, con mucho, intervino la confidencia y la traición desde dentro o desde los aledaños de la partida o "fracción»-puesto que el jefe máximo era Manuel García Ponce- dirigida por el bandido Andrés Santana Pérez (25). En principio, la única de estas muertes que parece tener relación, más o menos remota, con Sanguily es la de Pedro Palenzuela y Palenzuela.

En efecto, un telegrama cifrado del Jefe de Línea de Sabanilla, remitido a García Aldave desde Unión en horas de la mañana del 19 de julio de 1891, indicaba: «Acabo de capturar a Rafael Plasencia montado y armado. Caballo robado. Venía a conferenciar con Sanguily. Al ser detenido dijo llevaba comisión de V.S., quien le tenía ordenado diga no relleveta fucelo ni se dé cuenta de esta captura autoridades. Le tengo en lugar seguro hasta que V.S. diga disponga. Espero órdenes sobre el particular» (26).

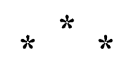

Los hermanos Antonio y Rafael Plasencio o Plasencia aparecen implicados en la muerte de Pedro Palenzuela y, de hecho, en el intento de aniquilación de los principales miembros de la partida de Manuel García Ponce, tanto en Matanzas como en la

(23) Jiménez Barreto a García Aldave, Potrero «Las Mulas» (Sabanilla), 29 de julio de 1891 (AGI. Diversos 17). Subrayado en el original.

(24) PAZ-SÁnCheZ [1], t. I, pág. 318 y sigs.

(25) Nos referimos a los óbitos de Antonio Mayor Delgado (Potrero «Esperanza" de Alfonso XII, 14 de abril), Andrés Santana Pérez (en terrenos de Ingenio "Mercedes", cerca de Cabezas, en la madrugada del 10 de agosto), Tomás Cruz (en los montes del Potrero "Valera», Bermeja, el 17 de agosto) y Pedro Palenzuela (en El Roque, el 21 de octubre).

(26) Transcripción de telegrama cifrado, Unión, 19 de julio de 1891 (AGI. Diversos 18). El primer subrayado es nuestro. 
provincia habanera. Rafael Plasencia, detenido a principios de julio de 1891, escapó, poco después, de una fuerza de la Guardia Civil que, a las órdenes del sargento Cabrera, lo conducía desde San Felipe a Batabanó, y, al mes siguiente, según se deduce de una carta que remitió el bandolero a cierto amigo, desmentía su supuesta muerte y daba a entender que se encontraba huido. Existe la posibilidad, sin embargo, a la vista del telegrama antes citado y de otros datos que expondremos a continuación, de que Rafael Plasencia decidiera colaborar con el Gabinete Particular desde el momento de su captura en julio de 1891 y que su huida de la Guardia Civil fuera, en realidad, una estratagema de García Aldave para facilitar sus trabajos confidenciales cerca de los auténticos insumisos.

Sea como fuere, lo cierto es que los hermanos Plasencia nos permiten un mayor acercamiento a una de las tramas confidenciales más importantes de la etapa de Polavieja, y que, como se verá con más detalle a continuación, el propio Julio Sanguily pudo estar informado del asunto, de ahí su rentabilidad para las autoridades coloniales. Se trataba, pues, de colaboradores díscolos pero, en cualquier caso, idóneos para los fines de la represión.

Sanguily, que se encontraba en La Habana el 11 de septiembre (27), no tardó en desplazarse al interior. El 6 de octubre, según una carta de Julio de la Jara -segundo jefe del Regimiento de Caballería de Pizarro-, el general insurrecto le había manifestado, en el paradero de Güines y en relación con los rumores de insurrección que circulaban por la provincia oriental, que "lo que se aseguraba es que Maceo venía en una expedición y Guillermón había desaparecido, creyéndose que será algo fraguado entre la gente de color, pues ellos nada sabían ni tenían trabajado ni pensado" (28).

Esta confidencia, tal vez manipulada conscientemente por Sanguily, debió producir algunas dudas en él ánimo del teniente coronel Julio de la Jara, quien volvió a referirse ahora

(27) Sanguily a García Aldave, Cerro, 11 de septiembre de 1891 (AGI. Diversos 18 ). "Le ruego me remita, con el portador, bajo sobre, el encargo que tiene para mí».

(28) La Jara a García Aldave, Güines, 6 de octubre de 1891 (AGI. Diversos 17).

R. I., 1996, n. 207 
en tono menos confiado, a las correrías de Sanguily. "Julio Sanguily fue hoy a Palos y mañana va a Melena, me llama la atención (a no tener alguna nueva favorable) tanto ir y venir de pueblo en pueblo, ¿quiere Vd. le ordene al celador le siga sus pasos cuando esté fuera de La Habana y ande por el campo, en un poco de tiempo?» (29).

Es muy probable que la respuesta de García Aldave a la pregunta anterior tuviera un carácter disuasorio, porque el Jefe del Gabinete Negro parecía estar muy al tanto de las actividades de Sanguily. En una de sus misivas a Polavieja, del 22 de octubre de 1891, puede leerse:

Mi objetivo principal es Manuel, a esto voy en todos mis trabajos, pero no desperdicio los demás que se presentan y siempre se irá aislando más y más, y perdiendo fuerza moral.

Lo de Jovellanos no sé si será un servicio a medias, pues hasta que no vea a Castillo nada puedo decir. Lo ofrecido eran seguros muertos Alfonso y Palenzuela, probable Víctor Cruz que se les había de incorporar, nada sé respecto de Alfonso, esto me tiene nervioso, espero hoy noticias que podré dar a Vd. (...).

Lo de Palenzuela causa efecto en los Palos, San Nicolás y toda la costa, pues era el práctico general de Manuel García en dichos puntos, así como Alfonso lo es de Guara y Melena.

Con figurar Castillo en el parte, se echa a perder el poder emplear a Rafael Plasencio contra Manuel García. Nada digo en concreto hasta que tenga noticias.

Conviene que Schmid escriba a J[ulio] S[anguily] (D. Pancho) para que le diga que por los Palos y la montaña se corre Gallo Sosa con otros dos mansos, que conviene concluir con los tres (30).

Esta carta, que completa la correspondencia cruzada entre los máximos responsables de la represión en el momento de la muerte de Palenzuela en El Roque (Jovellanos), nos ayuda a desvelar la intriga de su muerte, las repercusiones de la misma, la importancia de la trama confidencial para aislar al

(29) La Jara a García Aldave, Güines, 8 de octubre de 1891 (AGI. Diversos 17).

(30) García Aldave a Polavieja, San Felipe, 22 de octubre de 1891 (AGI. Diversos 19). 
propio Manuel García Ponce, el llamado Rey de los Campos y, como ya dijimos, abona la posibilidad de que el auténtico ejecutor del citado Palenzuela fuera, en realidad, Rafael Plasencia o Plasencio.

Por si fuera poco, otra epístola de García Aldave, correspondiente al día 30, apunta nuevos datos sobre el carácter descomedido que, a aquellas alturas, había alcanzado la labor represiva y torna a colocar, en la balanza de la sospecha, a don Julio Sanguily:

El Juez de Guara, Comandante de Voluntarios, se ve y habla con los bandidos, les da de comer y los esconde en la finca del Navío, esto lo sabía por muchos conductos, hoy me lo confirma Castillo a quien se lo ha dicho Alfonso. Se puede concluir con él al mismo tiempo que Alfonso, ¿qué le parece? La cosa tendría resonancia, pero se le encontraría al lado del bandido. Este es un Méndez de más baja estofa, pero que no deja de tener padrinos (31).

Gallo y Plasencia (32) se han ido para los Palos, nunca mejor que ahora para que Sanguily concluya con ellos, así se lo digo a Schmid para que le escriba apretándole bien las clavijas.

Aquí quedan Manuel, Vicente (33) y el Mesa que se les unió de la parte de Matanzas (34).

Ese mismo día, empero, Sanguily le enviaba a García Aldave, desde el ingenio "Concepción», una petición urgente para que no fuera trasladado el oficial Guerrero, pues ello convenía a los intereses de Pablo -seguramente Pablo Gallardo-, otro antiguo bandolero que colaboraba con el general insurrecto en las supuestas tareas confidenciales. "Tengo una guerrilla por Madruga. Por Palos y el Águila no hay nadie. Con el portador contésteme cerrada la carta, no sabe nada. También le su-

(31) Se refiere a Eustacio Méndez Rey, el Jefe de Voluntarios de Las Vueltas (Santa Clara), ejecutado por orden de Polavieja por secuestro y otros delitos.

(32) Se refiere a los bandidos Gallo Sosa, o sea, José I. Sosa Alfonso y a José Plasencia.

(33) Manuel y Vicente García Ponce.

(34) García Aldave a Polavieja, San Felipe, 30 de octubre de 1891 (AGI. Diversos 19).

R. I., 1996, n.o 207 
plico le dé a él una comunicación para Guerrero, que permanezca como antes, y él se la dejará de paso en Bermeja mañana, pues tiene órdenes de regresar mañana mismo». (35).

Paralelamente, Domingo Lavín, el famoso alcalde de Nueva Paz, en carta de la misma fecha, anunciaba la ausencia de su jurisdicción de José Palenzuela -hermano del difunto Pedro Palenzuela-, sobre el que se había cursado orden de detención, y quien desde luego, contaba con antecedentes penales y había pasado a residir a la zona de San José de los Ramos. Indicó, además, que Sosa Alfonso y el «mulato» José Plasencia habían almorzado, tres días antes, en casa de don Carlos Peña, vecino de Cabezas, y señaló, asimismo, que había recibido la visita de "Antonio Plasencia, a preguntarme si sería de buena fe lo que le propone Sanguily, yo le he dicho que sí, pero me parece que el mozo éste no va a hacer nada, lo veo muy desconfiado" (36).

Lavín, hombre bien informado por lo general, parecía apuntar hacia una mayor implicación de Sanguily en la trama contra Manuel García Ponce, extremo que, además, parece confirmar una nueva misiva de García Aldave a Polavieja:

Acabo de ver al celador Castillo y me asegura que Alfonso está ya con Manuel y que él espera muy en breve resultado positivo.

Cuando le he manifestado mi temor de que Manuel pudiera matar a Alfonso, me ha asegurado que nada temiese, que la cosa se hace y muy pronto. Que para el éxito se necesita no operar por el Navío. He suspendido en él todo movimiento.

Confirma lo dicho por Sanguily, de no estar con Manuel más que su hermano, Gallo y Plasencia por Calderón. En este último punto ya está hecho cuanto me pidió Sanguily (37).

Poco después, el oficial Benito Roig Fullana, que había contactado con Sanguily en el ingenio, «Concepción», recogía una

(35) Sanguily a García Aldave, Ing. "Concepción», 30 de octubre de 1891 (AGI. Diversos 19). Según su carta, Sanguily confiaba en que pronto se haría «algo» y no pensaba regresar a La Habana hasta ese momento.

(36) Lavín a García Aldave, Los Palos, 30 de octubre de 1891 (AGI. Diversos 17$)$.

(37) García Aldave a Polavieja, San Felipe, 19 de noviembre de 1891 (AGI. Diversos 19). 
información del Jefe de Línea de Sabanilla del Comendador, según la cual «hará unos díez días, vieron a Manuel García con el tuerto Matos, Plasencia y otro, por la Costa, entre Matanzas y Colón, afirmando que Vicente García no iba» (38). Podía tratarse de un simple rumor, aunque no debe olvidarse, sin embargo, la capacidad estratégica del Rey de los Campos que, en aquellos difíciles momentos, pudo esconderse en una zona un tanto alejada de su territorio habitual.

A principios de diciembre, no obstante, el optimismo del celador Castillo, según afirmaba García Aldave, estaba en su punto álgido:

Acabo de ver a Castillo, éste viene contentísimo por las noticias que recibe de Alfonso. Todos, hasta seis, están reunidos, como en breve bajarán para llevar a efecto el secuestro de Regalado, para entonces estará Castillo con gente suficiente en la casa donde comerá la gente antes de ir a llevarlo a efecto. Creo positivo el éxito y me ha pedido si cae en la emboscada Gallo y Vicente, la vida de Alfonso, la que en su nombre he prometido. Espera mucho y con fundamento. Yo no pido más que un poco de suerte.

Ayer escribí a Sanguily, le hablaba muy fuerte y le hacía comparaciones entre sus éxitos y el dinero gastado, manifestándole estaba Vd. ya cansado de gastar sin resultado, le ataco por hambre. Veremos lo que resulta (39).

Sanguily, por su lado, contestaba al Jefe del Gabinete asegurándole que tenía dos o tres hombres tras la pista de Manuel García Ponce y que sus intenciones eran buenas. "Aquí no se necesita a Marcos García, ni a nadie, puede Vd. decírselo así al General. Yo espero, dígaselo Vd., que lo que no hagamos nosotros no lo hará nadie. Que lo traigan. Yo quiero que antes de fin de mes quede todo concluido, haré lo que pueda, ¿lo conseguiré? Eso nadie puede asegurarlo. La suerte ha estado en contra [...] No me hablen más de M. García (Marcos), ni el quiere más al general, ni puede más que yo. Convenza Vd. a

(38) Roig Fullana a Guillermo Tort, Los Palos, 22 de noviembre de 1891 (AGI. Diversos 18).

(39) García Aldave a Polavieja, San Felipe, 4 de diciembre de 1891 (AGI. Diversos 19).

R. I., 1996, n.o 207 
S.E. de mis buenos deseos y de que la suerte, que es coqueta, ha coqueteado ya demasiado, que al fin cederá» (40).

En cualquier caso, parece que las presiones de García Aldave hicieron cierta mella en el ánimo del general maldito. En los días siguientes, su correspondencia con el Jefe del Gabinete se hace más frecuente, de ella se deducen sus viajes a Bermeja, Madruga y La Habana y su presencia, a finales de diciembre, en el consabido ingenio "Concepción». Asimismo, el día 16 de diciembre, aseguró que "el hombre -[Manuel García Ponce]debe volver a Guanamón [a] principios de [la] semana entrante», y no faltan, en sus epístolas, referencias a una previsible entrevista con el jefe bandolero, a las actividades de Barreto, uno de sus colaboradores y, ya en enero de 1892, a Pablo -tal vez Pablo Gallardo-, «he venido para ver si me da a Pablo, lo necesito por seis u ocho días, podía Vd. dármelo por la mañana para que se fuera conmigo por la tarde...", y a Apolonio Salgado, al parecer desterrado en Isla de Pinos (41).

Las esperanzas de capturar, a corto plazo, al invisible Manuel García Ponce reverdecieron a principios de febrero de 1892, pues, entre, otras cuestiones, parecía que Sanguily estaba dispuesto a colaborar de forma sincera y eficaz. «Estoy tocando todos los resortes, pero sin ver resultado inmediato. Según me dice Schmid, Sanguily tiene trabajos por Cocodrilo y Cuzco, más allá de Alfonso XII, esto me lo confirma Lavín, espero noticias más concretas», afirmaba García Aldave en carta a Lecumberri, ayudante de Polavieja (42).

José Schmid se había encontrado casualmente en La Habana, en la histórica Acera del Louvre, con Julio Sanguily, quien le manifestó que los trabajos iban bien y, sobre todo, le expresó

(40) Sanguily a García Aldave, Ing. "Concepción», 5 de diciembre de 1891 (AGI. Diversos 18).

(41) Sanguily a García Aldave, Bermeja, Madruga, "Concepción" y Cerro (en dos ocasiones), 7, 16, 28 de diciembre de 1891, 20 y 21 de enero de 1892, respectivamente (AGI. Diversos 18 ).

(42) García Aldave a Lecumberri, San Felipe, 2 de febrero de 1892 (AGI. Diversos 19). Las noticias facilitadas por Schmid, vía telegráfica, rezaban textualmente: "Trabajos preparatorios que dice tiene Sanguily hacen suponer que Manuel García se encuentra por Cocodrilo más allá de Alfonso XII» ( Febrero 2 de 1892. Noticias dadas por el comandante Schmid». AGI. Diversos 18). 
su decidido empeño de cara a colaborar en la caída del Rey de los Campos, como se deduce de las siguientes afirmaciones recogidas por el subjefe del Gabinete Particular (43):

Que había escrito a M. G. [Manuel García] y tenía seguridad de que recibió su carta; en la que le hablaba de que Manuel Sanguily había ido al Norte para trabajos revolucionarios (44), y que antes de que volviera, para dejarlo arreglado todo, convenía que se vieran.

Que si se ven, cumple lo ofrecido; que trabaja de buena fe; que se pedirá más dinero, aunque tenga que empeñar todo lo que posee y que M. G. se encontraba por Cocodrilo, que es lo que a V.S. importaba más y se lo comuniqué enseguida.

Polavieja, enterado de todo, ordenó que se recabasen más datos de Sanguily y que se contestase a García Aldave concretando las noticias, para no entorpecer los planes represivos. Schmid aseguraba, en la misma carta al Jefe del Gabinete, que Julio Sanguily "opina que, puesto que V. ha sabido la noticia por otro conducto, no hay inconveniente en que $\mathrm{V}$. haga todo lo que pensara hacer, pues M. G. le ha de citar [a Sanguily] pronto o le saldrá en caminos que le indique». Además, el general insurrecto había precisado "que por Cocodrilo, por la casa

(43) Schmid a García Aldave, La Habana, 2 de febrero de 1892 (AGI. Diversos 18). Manuel Sanguily, distinguido patriota y periodista cubano, era el propio hermano de Julio Sanguily (V. R. CEPEDA: Manuel Sanguily frente a la dominación yanqui. Ed. Letras Cubanas, La Habana, 1986, donde se afirma [pág. 23]: "Es bien sabido que Manuel Sanguily sentía y expresaba una profunda pasión por su hermano Julio, el valiente mayor general de la Guerra de los Diez Años que posteriormente perdió prestigio entre sus compañeros de armas por su tibia y desacertada participación en los preparativos de la del 95 y su tardía e ineficaz entrada en el campo de batalla, además de su manifiesta debilidad por el licor, el juego de azar y el parrandeo").

(44) Este viaje de Manuel Sanguily es verídico. «En 1891 fue nombrado profesor de geografía e historia en el colegio San Fernando. Ese mismo año viajó a Estados Unidos para entrevistarse con Martí. Regresó a Cuba a principios de 1892 [...] Al reiniciarse la guerra viajó a Estados Unidos. Desde allí gestionó la libertad de su hermano Julio, detenido en Cuba por las autoridades españolas, y trabajó en pro de la independencia. Regresó a Cuba en 1898 al ser designado delegado a la Asamblea de Santa Cruz" (Cfr. Instituto de Literatura y Lingüísticca de la Academia de Ciencias de Cuba: Diccionario de la Literatura cubana. Ed. Letras Cubanas, La Habana, 1984, págs. 946-948).

R. I., 1996, n. ${ }^{\circ} 207$ 
donde vive un tío de M. G. debe éste encontrarse y así se lo he dicho a V.S. esta noche por telégrafo. Dicho punto está hacia Zapata»(45).

Pero, en el fondo, don Julio Sanguily no tenía intenciones de entregar a Manuel García Ponce, aunque parezca increíble. Era un buen jugador y, como siempre, se guardó un as en la manga. Sí, es cierto que informó del viaje de su hermano al Norte para negocios revolucionarios, pero esta noticia, a juzgar por las palabras del propio Schmid, debía ser casi del dominio público, y, en cualquier caso, le resultaba útil para restablecer su confianza ante las autoridades coloniales. También es verdad que Sanguily supo convencer a su «amigo"Schmid de su sincero deseo de colaborar y, al cabo, consiguió que, una vèz más, el mismo Polavieja cayera en la trampa, pues, uno y otro se creyeron, ingenuamente, que tanto los movimientos de tropa como el resto de los trabajos represivos que se llevaban o llevarían a cabo bajo los designios de García Aldave no estaban en contradicción con las gestiones del general insurrecto, tal como se deduce de la misiva que Schmid dirigió, el día siguiente, al Jefe del Gabinete (46).

García Aldave, aficionado también al juego o, por lo menos, a las peleas de gallos, adivinó las intenciones de Sanguily. En carta a Polavieja, igualmente del día 3 de febrero, le informó con detalle de sus noticias y de sus cuidadosas gestiones, «para no ponerlos sobre aviso». Envió tras la pista de los bandidos a Clemente Rodríguez (47), desarmado y «como despedi-

(45) Schmid a García Aldave, La Habana, 2 de febrero de 1892, cit. «Esta misma noche he comunicado todo esto al Sr. General, después de mi entrevista con Sanguily".

(46) Schmid a García Aldave, La Habana, 3 de febrero de 1892 (AGI. Diversos 18). Esta carta dice así: "Señor Coronel: Dada cuenta al Sr. General de la conferencia que tuve de su orden con D. Julio Sanguily, dice, que se tenga en cuenta, que, puesto que para los trabajos de dicho señor no es obstáculo la persecución que pueda hacerse a Manuel García por la parte de Alfonso XII, [se atienda] el ofrecimiento hecho por el señor Morejón -[Abraham]- de obtener noticias, si por aquella zona penetraban los bandidos, así como que se trate de utilizar los elementos adictos que allí existen".

(47) En la ficha de Clemente Rodríguez, calificado como confidente por el Gabinete, se recoge este interesante testimonio, datado, al parecer, hacia mayo de 1891 (AGI. Diversos 18): «Efectivamente, yo conozco a M. G., como lo conocen todos los que viven en Santa Rosalía. Yo le he llevado de comer mu- 
do del servicio nuestro, para no infundir sospechas y él cree traerme noticias seguras de si están o no»; dedujo que el objetivo de los insumisos era esconderse en la Ciénaga de Zapata por algún tiempo y, en consecuencia, sugirió que fueran introducidas por el Maniadero fuerzas de Infantería que, en combinación con guerrilleros de los regimientos de María Cristina y San Quintín, que partirían de Colón y Yaguaramas, llevarían «la alarma a la Ciénaga y tal vez evitase que ellos se acogiesen en ella». Para ello, además, era necesaria la intervención de dos cañoneras que proveyesen de recursos a las citadas fuerzas desde Cienfuegos y Batabanó. Y, al mismo tiempo como decíamos, García Aldave intuyó las verdaderas intenciones de Sanguily (48):

Todo otro movimiento en donde dice Sanguily, aunque él me deja libertad de acción, lo creo contraproducente y que mañana si fracasa en sụ gestiones le servirá de pretexto. Vd. resolverá.

Tort iba a ser presentado en la Ciénaga a un señor D. Elías (49), muy conocedor de todos los bandidos, pero supe trabaja con Sanguily y le he dicho nada haga.

chísimas veces a los millos y a las cañas donde estaba oculto, pero que quiere V. que hiciera, cuando yo veía que otras personas muy pudientes lo protegían». A la pregunta sobre la identidad de tales personas respondió: "Pues bien, yo veía que muchas noches Don M. la T. [Mariano de la Torre], bajaba en su coche a casa de J. O. [Julián Osma] y allí se reunían Casuso, Sanguily y otros con M.G. y estaban de lechón y comilona y mientras tanto los de la partida estaban vigilando la casa para que nadie los sorprendiera. ¿Con estas cosas y otras mil circunstancias, como quiere V. que yo hiciera nada contra M. G.? Yo cuando el Sr. Coronel me ha llamado o he sabido que me andaban buscando, fui dos veces con Don M. la T. y le contaba lo que me pasaba y él lo primero que me decía era: iCuidado con el bandido, allá el Gobierno que lo coja!, a ti el bandido puede cortarte la cabeza si se entera que lo andas entregando. Déjalo, allá ellos./. Yo cuando el asunto de Quivicán le dije a J. $O$. donde estaba M. G. y ni siquiera caso me hizo. ¿Con estas cosas que quiere V. que ${ }^{i}$ yo haga? Hoy por hoy no sé por donde anda, porque nadie se fía de decirme nada, pero esté V. seguro que alguien de los grandes lo protegen".

(48) García Aldave a Polavieja, San Felipe, 3 de febrero de 1892 (AGI. Diversos 19).

(49) El tal don Elías era, según parece, don Elías Delgado, vecino, en realidad, de la Cidra. En nota referida a este individuo se lee lo siguiente (AGI. Diversos 16: Hay una anotación de García Aldave: «Febrero 3/92. Quedó auto- 
El Jefe del Gabinete cambió, aparentemente, de opinión y autorizó la entrevista entre el teniente coronel Tort y el citado don Elías Delgado, la que tuvo lugar a mediados de mes. "Le diré del don Elías, que no ha querido espontanearse y dice que no ve a M[anuel] G[arcía] desde que llamándose Ricardo Alonso lo tuvo él trabajando siendo capataz de carretas en la Cidra y que, después, que no ha sabido que esté más por allí, porque como estuvo cuatro años preso, desconfió de él», afirmó Tort en una extensa carta a García Aldave. Su entrevistado le aseguró, también, que el "depositario» y persona de toda confianza «del Bandido allí es don Tomás Fernández, que tiene arrendado el potrero 'El Siboney', donde vive y que, además, tiene una tienda en la misma Cidra, en sociedad con su hermano José; que en dicho potrero 'Siboney' tiene una colonia de caña y que si M. G. va por allí con seguridad es aquél su paradero» (50).

Asimismo "hechas las proposiciones y ofrecimientos, dijo que él -[Elías Delgado]- no se podía comprometer porque estaba muy viejo y medio ciego y que M. G. no se fiaba de él; que lo conoce mucho, sí, y a Gallo Sosa, pero que los otros que andan con éstos son nuevos para él y no los conoce, insistiendo en que hace muchos años que no los ve». Tort apuntó, igualmente, que su entrevistado era «mayoral del potrero del Ingenio 'Concepción' y, preguntándole si conocía a Sanguily, dijo sonriéndose que muchísimo, porque lo ve allí con mucha frecuencia con muchos jugadores, pero que no sabe que tenga tratos ni contratos con los Bandidos, lo que me prueba que aquí hay gato encerrado y que él es un tuno de siete suelas» (51).

La carta de Tort es útil, además, porque adelanta otro dato significativo. La existencia, en la misma zona, de un colabora-

rizado Teniente Coronel Tort con las reservas consiguientes»): «La persona que me quieren presentar en Matanzas es un tal don Elías Delgado, que vive en la Cifra, término municipal de Santana, entre Matanzas y Sabanilla. Conoce personalmente a todos los bandidos, pero tengo entendido trabaja con Sanguily. Ruego a V.S. me diga si por esta circunstancia dejo de verlo, en cuyo caso no tengo necesidad de ir más que a la Mocha, donde con motivo de las fiestas veré a otras personas». sos 19$)$.

(50) Tort a García Aldave, Matanzas, 14 de febrero de 1892 (AGI. Diver-

(51) Ibidem. 
dor del Gabinete Particular, conocido por Don Pancho, pero que no se corresponde con el nombre clave de Julio Sanguily. Este individuo, que mantenía estrechos contactos con Guillermo Tort, resultaba ser, según el teniente coronel, una persona de confianza, decidido y experto perseguidor de insumisos que tenía un hermano boticario en Matanzas. Ambos realizaron diversas gestiones para capturar a Manuel García Ponce, pero, como tantas otras, estuvieron condenadas al fracaso (52).

Mientras tanto, García Aldave parecía entusiasmarse con la posibilidad de una inminente caída del Rey de los Campos, mediante los trabajos de Castillo, al que exigió resultados inmediatos. "Me asegura el resultado de su ofrecimiento, pues acaba de ver al que se lo había hecho y le respondía con su cabeza. Además hay otra circunstancia, Plasencio, no el bandido, sino el que mató a Palenzuela, sabe que su hermano no tiene más salvación para salir de presidio que la muerte de Manuel García. La noticia de que está en San Nicolás es casi segura, pues además de lo que ofrecen a Castillo, le han dicho el sitio al teniente Roig y el confidente que tiene en Matanzas Tort lo ha llamado para decirle lo mismo» (53).

Pero no podían faltar, una vez más, las referencias a Julio Sanguily, valiosas por cierto, porque constituyen una prueba más de la capacidad de intriga y de la estrategia de "medias verdades» del general insurrecto, así como de su habilidad para ganarse a Schmid, lo que, de paso, le sirvió para crear dificultades en la relación, no exenta de tensiones, entre el Jefe y el Subjefe del Gabinete Negro:

Vi, ayer, a Sanguily en el tren, me dijo que trabajaba con esperanzas de éxito y que cubría la mercancía con falsos tra-

(52) Ibidem. V., además, la correspondencia de Tort con referencia a los trabajos de este segundo Don Pancho: Tort a García Aldave, Matanzas, Madruga, Aguacate, 22, 23, 24 y 25 de febrero y 2, 5, 14, 19 y 20 de marzo de 1892 (AGI. Diversos 19).

(53) García Aldave a Polavieja, San Felipe, 23 de febrero de 1892 (AGI. Diversos 19).

R. I., 1996, n. ${ }^{\circ} 207$ 
bajos separatistas, único medio para capturar al otro. Vd. que tiene todos los datos de este último juzgará.

Además me dijo que Schmid le había dado un volante firmado por él (cosa para lo que no está autorizado), para comunicar con clave, una clave especial y la orden para que fuera a él a quien comunicase la muerte (en caso de éxito) de Manuel García, para ser él, el que fuera a recoger el cadáver y dar el parte. Esto se hace a raíz de tener un disgusto conmigo y cuando llego se me dice que Sanguily pidió la clave y que quiere entenderse mejor que con San Felipe -[García Aldave]- con La Habana -[Schmid]- y nada de la última parte. Yo, como Vd. comprenderá mi General, no tengo inconveniente de quitar la careta a este Señor, pero que Vd. no querrá escándalos por lo que le suplico que dé la orden, fundado en la necesidad de que haga sus preparativos para el viaje, de que hoy mismo, a ser posible, entregue al Oficial 1.० de Archivo, Don Mauro Guzmán, la oficina del Gabinete y creo que ganaríamos todos con que marchase cuanto antes para la Península (54).

Don Julio Sanguily, por su parte, le escribió dos días después, "he estado en el punto que Vd. sabe y sigo mañana para Mocha y Aguacate. El sábado por la tarde o domingo por la mañana iré a La Habana» (55). Poco después, García Aldave le extendió, en la capital, una clave cifrada para entenderse con él (56). Y, al siguiente día, Sanguily volvió por sus fueros y le pidió un anticipo de ciento setenta y cinco pesos en oro, única forma de marchar hacia el interior, debido a que no tenía "un medio, pues lo de ayer lo dediqué, a la casa» (57).

García Aldave se indignó una vez más. «El otro día -escribió al capitán general-, quise salvar a Vd. del sablazo de Sanguily, a medias, pero hoy le remito la carta que me envía hoy y copia

(54) Ibidem

(55) Sanguily a García Aldave, "La Paloma», 25 de febrero de 1892 (AGI. Diversos 18).

(56) Clave reservada para entenderse con don Julio Sanguily y con el coronel jefe del Gabinete Particular, La Habana, 28 de febrero de 1892 (AGI. Diversos 18). La reproducimos en facsímil en el t. II de nuestro libro ya mencionado sobre el bandolerismo cubano.

(57) Sanguily a García Aldave, Cerro, 29 de febrero de 1892 (AGI. Diver$\operatorname{sos} 19)$. 
de la que yo le contesto. Vd. mi general pesará todas las razones, verá si conviene aguantar este nuevo sacrificio o mandarlo a paseo [...]. Son 175 pesos más tirados» (58). Sin embargo, la Capitanía General accedió a entregarle ciento cincuenta pesos, "últimos, pero de verdad», como subrayó Lecumberri (59).

El Jefe del Gabinete se disculpó también, pues de algún modo se sentía responsable de la ineficacia de Sanguily y de sus continuas peticiones de numerario. "Mucho me alegraré sean ya de verdad los últimos 150 que se le dan a nuestro buen amigo Sanguily. Vd. comprenderá que yo no tengo más remedio que ofrecerle apoyo, en Vdes. está en decirme que no hay un centavo, [...], por otra parte tan pronto como el general me diga rompa, Vd. sabe que me sobran alientos para ello y que se compagina mejor con mi carácter esta última situación» (60).

El «buen amigo" Sanguily se desplazó a Matanzas y, entre el 5 y el 14 de marzo, estuvo en el ingenio "Concepción", en Bermeja y, por último, ya de regreso a La Habana, en San Felipe. Solicitó unos días de permiso o de descanso para Pablo, quizá Pablo Gallardo, que al parecer, se encontraba desesperado, se desplazó a La Güira tras la pista de Manuel García Ponce, según afirmó (61), y, por último, aseguró, desde su casa del Cerro, que era «incierto que José Plasencia anduviera por Santa Rosa, ni que M. G. estuviera por la Güira. Lo anduve todo", $\mathrm{y}$, añadió, en un gesto de malévola ingenuidad: "Sírvase mandarme los permisos que le pedí. Espero contestación a ésta, ya que las otras no lo han sido. ¿Se está Vd. cansando ya de mí?» (62).

Manuel García Ponce se encontraba, según una confidencia obtenida por Guillermo Tort, cerca del ingenio "Alcancía» de Bemba (Jovellanos), «con toda la gente a caballo y que él mon-

(58) García Aldave a Polavieja, San Felipe, 1. de marzo de 1892 (AGI. Diversos 19).

(59) Lecumberri a García Aldave, La Habana, 1. de marzo de 1892 (AGI. Diversos 17).

(60) García Aldave a Lecumberri, San Felipe, 2 de marzo de 1892 (AGI. Diversos 19).

(61) Sanguily a García Aldave, "Concepción» y Bermeja, 5, 8 y 9 de marzo de 1892 (AGI. Diversos 18).

(62) Sanguily a García Aldave, Cerro, 14 de marzo de 1892 (AGI. Diver$\operatorname{sos} 18)$.

R. I., 1996, n.o 207 
ta uno alazán colorado» (63). Pero, al margen de la veracidad de esta noticia, no faltaron argumentos para pensar que, ciertamente, Sanguily no estaba dispuesto a entregar a los bandidos y que, en realidad, daba pistas erróneas sobre su situación, tal como parece rectificar otro testimonio de Don Pancho recogido por Tort:

Hablé con Don Pancho por la mañana en Aguacate y cree que la gente esté por Unión de Reyes y Alfonso XII, pues le han asegurado que un tal Don Rafael Acosta, maquinista del Ingenio Carmen de Crespo, que es muy amigo de M. G., lo oculta por allí. Dice que también le han asegurado que Sanguily sale con mucha frecuencia de noche, acompañado de tres mulatos, uno de ellos llamado Matilde y que todo hace creer habla con ellos... (64).

Pese a todo, Sanguily siguió pidiendo dinero y realizando sus tejemanejes entre La Habana y Matanzas (65). Todo indica que, en el fondo, nunca tuvo intención de vender a los bandoleros, pues, como al parecer afirmó en cierta ocasión, no eran tales insumisos sino, muy al contrario, patriotas que luchaban por la ansiada independencia nacional.

\section{LoS ALZAMIENTOS OCCIDENTALES DEL 24 DE FEBRERO}

Todo estaba preparado para el alzamiento general que, conscientemente, se hizo coincidir con el carnaval, para no llamar la atención de las autoridades coloniales que, de otra manera, pudieran extrañarse por las inusuales agrupaciones de personas en distintos lugares del campo. La Junta Revolucionaria habanera se reunió el 17 de febrero, estando presentes Juan Gualberto Gómez, el general Julio Sanguily, José M. a Aguirre, Pedro Betancourt, López Coloma, Martín Marrero, Joaquín

(63) Tort a García Aldave, Madruga, 18 de marzo de 1892 (AGI. Diversos 19). La confidencia fue dada a Don Pancho citado más arriba.

(64) Tort a García Aldave, San Felipe, 27 de marzo de 1892 (AGI. Diver$\operatorname{sos} 19)$.

(65) Sanguily a García Aldave, Cerro y Aguacate, 20 de abril y 26 de mayo de 1892 (AGI. Diversos 18). 
Pedroso y Pedro y Guillermo Acevedo, «decidiéndose que el alzamiento se verificara el 24 y que los jefes se ocultaran desde el día 20 para evitar ser detenidos» (66).

El día 22 se presentó López Coloma al general Sanguily para recibir órdenes, y, al día siguiente, salió de La Habana junto con Juan G. Gómez, Juan T. Latapier, Loret de Mola, José María Treviño, Federico Núñez, Francisco Regueira, Antonio M. Rivero, Rafael Rosado, José Villar, Gerardo Núñez y Alberto Casaus, "desembarcando en el paradero de Ibarra, próximo a Guanábana y a la capital de la provincia, desde donde se dirigieron al demolido ingenio 'La Ignacia', que tenía arrendado Coloma, en cuyo lugar y en la finca de Manuel Hernández, en Canimar, se depositaron las armas» (67).

Según el polígrafo matancero, en "La Ignacia» se incorporaron Gregorio y Alfonso Ibarra, mientras que, al intentar salir de Aguada de Pasajeros, fue muerto, el día 24, Antonio Curbelo. En la mencionada finca debían concentrarse, además, los «diversos grupos, entre ellos el de los hermanos Pedro y Guillermo Acevedo; el de Manuel García, con cincuenta hombres, y el de José D. Amieva, Gerardo Domenech y otros, que saldrían de Matanzas. En total: debían haberse reunido en aquel ingenio unos cuatrocientos patriotas, los cuales marcharían acto continuo sobre Matanzas, a la que sorprenderían en pleno carnaval» (68). Pero pronto comenzaron los problemas.

López Coloma recibió, a las seis de la mañana del día 24, un aviso del jefe de la estación de Ibarra, su primo Francisco Valdés Coloma, en el que le indicaba que la conspiración había sido descubierta y que, en aquellos momentos, salía un tren con tropas para perseguirlos, por lo que decidió lanzarse al campo con sus 16 hombres. Sin embargo, esto no fue lo peor:

Manuel García [...], a quien el general Julio Sanguily, como jefe del Departamento Occidental había expedido el nombramiento de comandante de la Revolución, fue muerto

(66) C. M. Trelles y Govin: Matanzas en la Independencia de Cuba. Imp. "Avisador Comercial», La Habana, 1928, pág. 46.

(67) Idem, págs. 46-47.

(68) Idem, pág. 47.

R. I., 1996, n. ${ }^{\circ} 207$ 
en Seborucal, Ceiba Mocha, en la noche del 24 de febrero, a las pocas horas de haberse sublevado.

Existen diversas versiones relativas a este extraño suceso. Manuel Sanguily creía que a García lo había asesinado un mercenario, que se había unido ese mismo día a la partida y fue pagado por un conocido hacendado habanero. Vicente García, hermano de Manuel, publicó una carta en' «La Lucha» el 23 de marzo de 1895, diciendo que los dos prácticos que tenía Manuel ese día eran Fidel Fundora y Alfredo Ponce. Y el Sr. Eduardo Varela Zequeira en su artículo ¿Quién dio muerte a Manuel García? («Heraldo de Cuba», abril 1 de 1914), indica que el citado Sr. Alfredo Ponce y Martell, persona de buenos antecendentes, que se incorporó en dicho día a la partida, fue el que lo mató casualmente al ocurrir un tiroteo con la Guardia Civil (69).

Pero sobre la muerte de Manuel García escribiremos seguidamente. Mientras tanto, el grupo de Coloma fue atacado, el 28, en el Cueval de Santa Elena, cerca de «La Ignacia» y hecho prisionero, «lo que no es de extrañar teniendo en cuenta el corto número de sus componentes y su inexperiencia militar". Juan Gualberto Gómez y López Coloma fueron detenidos rápidamente, $\mathrm{y}$, más tarde, el primero fue desterrado a Ceuta, mientras que el segundo corrió con peor fortuna, pues fue fusilado en noviembre de 1896 (70).

Ahora bien, la intentona de Ibarra -a la que habría que sumar el frustrante alzamiento de Manuel García Ponce y sus hombres iniciado en Seborucal (Ceiba Mocha)-, con ser la más destacada por su trascendencia histórica, no fue la única del Occidente insular. En la noche del 24 de febrero se sublevó, en Jagüey Grande, el doctor Martín Marrero al frente de 39 hombres armados, entre los que estaban José Agustín y Aurelio Rodríguez. Estos insurrectos tuvieron un encuentro, dos días después, con fuerzas del Regimiento de María Cristina, «haciéndoles algunas bajas». Martín Marrero se acogió a indulto el 3 de marzo y fue deportado a España (71), aunque, tiempo después, consiguió fugarse y se reincorporó a la guerra.

(69) Idem, págs. 47-48.

(70) Idem, págs. 48-49.

(71) Idem, pág. 49. 
Paralelamente, el 24 de febrero también se alzó en Los Charcones (Aguada de Pasajeros), el hacendado y teniente coronel insurrecto Joaquín Pedroso, junto con Alfredo Arango y Charles y Jorge Aguirre. Este levantamiento, aunque se produjo en una zona de la provincia de Las Villas, estaba íntimamente ligado a los anteriores, sobre todo al de Jagüey Grande. Según Trelles, a los once primeros alzados se unieron, en días sucesivos, las partidas capitaneadas por antiguos bandolerosinsurrectos, como José Álvarez Arteaga, Matagás; Regino Alfonso y el Tuerto Matos (72), hombres expertos y audaces que persistieron en la lucha, a pesar de que, poco tiempo después se vieron obligados a acogerse a indulto Pedroso, Arango y otros insurrectos de la comarca (73).

En efecto, Martín Marrero aseguró que el grupo de Aguada de Pasajeros «estaba formado por la partida de Matagás, engrosada por un buen grupo de hombres armados" y que estas fuerzas, "como la de Manuel García, contaban también con gente acostumbrada a la vida de campaña y desde luego con buenos prácticos...» (74). En este sentido, la prensa se hizo eco, el día 27 de febrero, de la incorporación de Álvarez Arteaga al alzamiento: "El comandante militar de Colón tiene noticias de que una partida formada en las inmediaciones de dicho partido se dirige a Jagüey Chico, para unirse a otra partida que debe levantarse capitaneada por Matagás» (75).

El 4 de marzo se produjo un enfrentamiento en Saratoga (Cienfuegos), con el resultado de once bajas por parte española. Con todo, sólo permanecieron sobre las armas Álvarez Arteaga y Matos, que se internaron en la Ciénaga de Zapata, mientras que, hacia el 24 de abril, hizo «acto de presencia en el ingenio 'Ponce', cerca de Cárdenas, la partida de Regino Alfonso" (76).

Los bandoleros-insurrectos, pues, se convirtieron en jefes mambises de indudable prestigio $\mathrm{y}$, al paso de la Invasión de

(72) Idem, págs. 49-50.

(73) V. J. FERNÁNDEZ FERNÁNDEZ: "Los alzamientos revolucionarios del 24 de febrero de 1895 en el Occidente de Cuba», Tebeto. Anuario del Archivo Histórico Insular de Fuerteventura, t. IV, 1991, págs. 109-129.

(74) V. "Diario de operaciones de Martín Marrero», en: ANC.

(75) V. "Nueva partida», La Aurora del Yamurí, Matanzas, 27 de febrero de 1895.

(76) C. M. Trelles y Govín, [65], pág. 51.

\section{R. I., 1996, n. ${ }^{\circ} 207$}


Gómez y Maceo, les fueron reconocidos sus méritos. Estos hombres, que se encontraban fuera de la ley desde mucho antes del estallido revolucionario, no podían permitirse el lujo de acogerse a ninguna medida conciliadora del gobierno colonial, por ello, y por propia idiosincrasia, se mantuvieron en pie de guerra con la esperanza en un porvenir de justicia y equidad, que ahora veían más próximo.

Ahora bien, sería la provincia de Oriente, con su vieja tradición insurrecta, la avanzada y el sostén -también en esta ocasión- de la revolución emancipadora hasta la estabilidad de la contienda, pero, no por ello debe ignorarse la importancia de la intentona occidental, pese al fracaso, en términos generales, del alzamiento, donde un hombre tan significativo como Manuel García Ponce no pudo combatir, a su pesar, en la guerra independentista. Como recuerda Trelles, "la causa principal del fracaso del movimiento en Matanzas se debió a la prisión del citado General (Julio Sanguily). Si él hubiera atendido a las instancias de Juan Gualberto, que le rogaba que desde el 20 desapareciese o se ocultase; o si hubiera seguido el consejo que le dio su ilustre hermano Manuel el 23 por la tarde, de irse a esconderse, y si hubiera podido estar en Ibarra el 24, la revolución habría tomado gran incremento no sólo en la provincia matancera sino en las inmediatas y es casi seguro que el problema de Cuba se hubiera resuelto mucho más pronto» (77).

En relación con el citado comportamiento de Julio Sanguily -quien, lo mismo que José María Aguirre incumplió, efectivamente, el acuerdo de abandonar la capital y/u ocultarse el día 20 de febrero-, subraya Toledo Sande que "una parte del esfuerzo de Juan Gualberto por lograr la oportuna salida de La Habana, fue una discusión con él y con Manuel Sanguily el día 22 , pues este último -a quien el otro había confiado el secreto del acuèrdo del alzamiento para el 24-, consideraba necesario disuadir a su hermano de ese proyecto insurreccional, por estimar que aún no había condiciones en la Isla para levantarse. Y en aquella discusión Juan Gualberto logró que el general Sanguily ratificara su compromiso de levantarse...» (78).

(77) Idem, pág. 50.

(78) L. TOLEDO SANDE: «José Martí y Juan Gualberto Gómez», cit. en M. de PAZ SÁNChEZ, [1], t. II, págs. 142 y 152. 
Los alzados de "La Ignacia», sin la oportuna dirección militar que hubiera podido ejercer Julio Sanguily y José María Aguirre y, asimismo, bajo la presión moral de otras importantes ausencias como las de Pedro Betancourt y los Acevedo, trataron de cumplir, con enormes dificultades, su compromiso revolucionario, antes de caer en manos de las autoridades coloniales. "Partidas armadas, sin cohesión ni disciplina, recorrían los campos -ha escrito José L. Franco-. Mientras Julio Sanguily y José María Aguirre eran detenidos, Juan Gualberto, que era un civil y estaba destinado a participar en el futuro gobierno, se alzó en Ibarra, Matanzas, acompañado de López Coloma, Latapier, Loret de Mola y once compañeros más. Manuel García, el famoso bandido, con cuya capacidad guerrillera se contaba para el inicio de las operaciones en Matanzas y La Habana, fue asesinado por un sacerdote español al intentar incorporarse a las filas de la Revolución. El doctor Pedro Betancourt tuvo que emigrar...» (79).

Las últimas frases de Franco tornan a introducirnos en el largo debate acerca de la muerte de Manuel García Ponce, que, como decíamos, también resulta crucial para entender el fracaso del movimiento revolucionario occidental en febrero de 1895.

\section{3. ¿Quién mató a Manuel García?}

El 24 de febrero de 1895, en horas avanzadas de la tarde, hicieron acto de presencia en la tienda del Seborucal (Ceiba Mocha), entre veinte y cincuenta hombres armados a las órdenes de Manuel García Ponce. José Fraguela, dueño de la tienda, entregó, contra un recibo que le extendió el jefe rebelde en nombre de la República de Cuba (80), cierta cantidad de dinero y víveres. Poco después, se produjo la muerte del cabecilla.

(79) J. L. Franco: Antonio Maceo. Apuntes para una historia de su vida. Ed. Ciencias Sociales, La Habana, 1975, t. II, págs. 90-91.

(80) M. POumIER: Contribution à l'étude du banditisme social à Cuba. L'histoire et le mythe de Manuel Garcia "Rey de los Campos de Cuba» (1851-1895). Ed. L'Harmattan, París, pág. 124.

R. I., 1996, n. 207 
¿Cómo sucedieron los hechos?, existen diferentes versiones $\mathrm{y}$ testimonios $\mathrm{y}$, tal como hemos apuntado, el misterio ha rodeado este suceso, sin duda relevante en relación con la propia biografía del insumiso y con el fracaso del alzamiento insurrecto occidental.

El general Loynaz del Castillo destaca, en sus Memorias, la importancia del antiguo bandolero dentro del plan revolucionario de Matanzas, y subraya que Pedro Betancourt contaba con él para que le sirviese de guía y escolta, "por ello le dio cita para el alzamiento». El relato de este autor hace referencia al pago, en la tienda ya mencionada, con «vales suscritos a nombre de la República»y, a continuación, asume el testimonio de Eliseo Figueroa en relación con la muerte del bandolero-insurrecto:

Sin incidentes, continuó su marcha. Poco después, avisado Manuel García de alguna novedad en el camino, partió a galope a reconocer, acompañado del práctico Fundora, ambos tercerola en mano, mientras la fuerza hacía alto para aguardar. Minutos después oyéronse dos disparos hacia donde se encaminaban el Jefe y su acompañante. Allí acudieron, presurosos, todos los de la partida. Tendido en el suelo encontraron el cadáver de Manuel García, cerca de su caballo; pero Fundora había desaparecido. En vano le vocearon y buscaron; instantáneamente sospecharon la traición; el asesinato del jefe en que tantas esperanzas se cifraban. Desesperado por el crimen, Vicente, hermano de Manuel García, dispuso que se retiraran todos los reclutados, para la guerra, quedando solamente en el campo los componentes de la antigua partida y abandonando un caballo cargado de armas, la bandera y otros efectos, que más tarde fueron a poder del general Prats. Recogió al hermano muerto y lo condujo a una casa donde fue velado y enterrado, y más tarde exhumado e identificado por las autoridades militares (81).

(81) E. Loynaz del CASTillo: Memorias de la Guerra. La Habana, 1989, págs. 134-135. Añade este autor, citando unas frases de Martín Marrero a Segundo Corvisón, que "Manuel García tuvo desconfianza del práctico que le envió el doctor Betancourt para conducirlo donde él, mandándole a decir que ése no era patriota, sino un bandolero. Pero luego, desistiendo de sus recelos, mandó a decirle a Betancourt que sí se lo mandara porque era muy práctico. Ese práctico, según el coronel Figueroa, era Fundora: el único acom- 
Uno de los documentos más próximos, cronológicamente al acontecimiento, empero, es el parte que el oficial de la Guardia Civil Luis Rabadán Terrón o Terro dirigió desde Ceiba Mocha, el 28 de febrero de 1895, al gobernador de Matanzas. Según esta fuente, en torno a las nueve y media de la noche del día 24, se presentó al oficial español el guardia segundo Vicente Pérez García, «que venía en unión de la fuerza del puesto de Canasí, manifestándome que se había adelantado de ésta y que, al pasar por la tienda de Seborucal, encontró un grupo de hombres a caballo en número de 20 ó 30, los que le hicieron algunos disparos hiriéndole en el brazo derecho» (82). A raíz de esta noticia, Rabadán emprendió la persecución y su relato es el siguiente:

Inmediatamente salí con la fuerza disponible enterándome en la expresada tienda [que] se había presentado allí el bandido Manuel García y su partida, robándole dinero y efectos y matando a machetazos al paisano don Felipe Díaz; seguidamente continuó la persecución a la dirección que llevaba la partida que era la del camino de Matanzas, encontrando al poco rato y al lado de un portillo abierto en una cerca de piedra el cadáver de un hombre que por su fisonomía y haberle encontrado varias cápsulas de rifle y revólver comprendí era de la partida y que muy bien puede ser el hombre a quien mandé hacer varios disparos antes de llegar a la expresada tienda por huir al darle el alto por tercera vez, encontrando también un caballo con montura mejicana de gran alzada que supuse era el que montaba el cadáver, al lado de éste encontré una bestia con aparejo, en la que parece pre-

pañante de Manuel García en el momento de su alevosa muerte, el que inmediatamente desapareció" (pág. 135).

(82) Vicente Pérez García, guardia civil de segunda clase: pertenecía al 17..$^{\circ}$ tercio de la Guardia Civil en Cuba, comandancia de Matanzas, a la que se había integrado desde principios de 1893, cumpliendo varios destinos en la comarca. Según su hoja de servicios: «el 24 de febrero [de 1895] fue herido en un brazo por la partida de Manuel García, alzada en sentido separatista en la tienda Seborucal, pasando con tal motivo el 26 de dicho mes al Hospital de La Habana». Por Real Orden del 6 de junio de 1895 se le concedió "la Cruz roja del Mérito Militar con la pensión vitalicia de siete pesetas cincuenta céntimos, como recompensa de la herida que recibió en el encuentro con la partida de Manuel García la noche del 24 de febrero anterior» (AGM. Sección 1. a División 1. a legajo P-1281). 
tendían trasladarlo y creyéndole de importancia por su traje, caballo y demás creí prudente ponerlo en sitio resguardado, disponiendo se colocara sobre la bestia llevándola a la casa de don Miguel Romero, desde donde continué la persecución encontrando después otro cadáver de un hombre de color sobre el camino real de Matanzas... (83).

Tras avisar para que recogieran los cadáveres, por considerar preferente la búsqueda de la partida, según sus propias palabras, Luis Rabadán continuó la persecución mediante el rastro dejado por los rebeldes, «encontrando varios portillos y cercas abiertas en dirección a Montes de Oro es donde interrogué a varias personas acerca del rumbo de dicha partida, enterándome confidencialmente de que el bandido muerto era Manuel García, pasando después a ésta, pero como aún no se había confirmado esto, me abstuve de comunicarlo oficialmente hasta que regresé en el día de ayer, después de cumplimentar el servicio que en el anterior se me ordenaba, habiendo sido también recogidos otros dos caballos con montura y un hule con una hamaca y otras prendas de ropa, todo perteneciente a la partida" (84).

Un día antes, La Aurora de Yumurí había publicado la siguiente noticia:

El coronel de la Guardia Civil señor Tort, en telegrama de ayer decía al Gobierno Regional, que anoche el bandido Manuel García con su partida, que ha aumentado hasta 16 miembros, asaltó y robó la tienda de Seborucal, término de Ceiba Mocha, provincia de Matanzas, haciendo fuego y matando al paisano Felipe Díaz, vecino de Canasí e hiriendo a un guardia civil que se dirigía hacia aquel lugar (85).

Esta nota avala, en parte, las afirmaciones de Rabadán, sobre todo en relación con las dudas acerca de la identidad del

(83) Luis Rabadán Terrón al gobernador de Matanzas, Ceiba Mocha, 28 de febrero de 1895. AHPM. Gobierno Provincial, Orden Público, BandolerosInsurrectos, Leg. 1, n.o 111.

(84) Ibidem.

(85) "Manuel García y su partida», La Aurora del Yumuri, Matanzas, 27 de febrero de 1895. 
cadáver. Poco después, sin embargo, otro periódico, La Caricatura (86), publicó una información que atribuía el protagonismo, aunque casual, de la muerte de Manuel García Ponce a Felipe Díaz, el paisano mencionado más arriba, quien, al parecer, también poseía el empleo de sacristán, al tiempo que ejercía como guardia municipal de Canasí.

Por otro lado, Vicente García Ponce remitió una carta, ya mencionada, al director de La Lucha, que publicó el día 23 de marzo de 1895, en la que daba su versión de los hechos:

Habiendo salido de la bodega del Saborucal cogimos el camino que conduce a Matanzas. Mi hermano tomó la vanguardia y yo la retaguardia y a un kilómetro de la bodega sentí tres tiros y encontré a mi hermano muerto y a un pardo desconocido, y aquí la duda que el pardo no tenía armas de fuego ni mi hermano quemó ningún cartucho según se explica por el arma que llevaba. De manera sea que allí entró la confusión y yo dispuse llevarme a mi hermano para enterrarlo; y a la mucha distancia de haber caminado para enterrarlo, pensé ponerlo en un camino para que lo identificaran y descansara en paz; y Fidel Fundora y un individuo que dijo llamarse Alfredo Ponce (que fueron los dos prácticos que mandó el médico Betancourt de Matanzas para que nos dirigiera a Ibarra), cuando resultó la novedad que antes de esto le explico, entonces Fundora y su compañero siguieron la dirección que llevaban con toda la demás gente, según dicen a ponerse a las órdenes del médico Betancourt (87).

Se deduce, al menos, que las dos últimas personas que vieron con vida a Manuel García Ponce fueron Fidel Fundora y Alfredo Ponce, los dos prácticos enviados por el general Betancourt. Fundora, en declaraciones muy posteriores a Varela Zaqueira, expuso la versión de la muerte del cabecilla en una escaramuza con fuerzas españolas (88), aunque, como apuntamos más arriba, también pudo ocurrir que un disparo fortuito de Alfredo Ponce, inexperto por lo que parece en lides comba-

(86) Del 3 de marzo de 1895. V., también, J. FERNÁNDEZ, [73], pág. 125.

(87) Reproducida en M. PoumIER, [80], pág. 397.

(88) J. FERNÁNDEZ, [73], pág. 126.

R. I., 1996, n.o 207 
tivas, acabara con la vida del jefe insurrecto. Después, todo fue confusión y nerviosismo.

Eliseo Figueroa, miembro de la fuerza insurrecta y, más tarde, coronel del Ejército Libertador, siempre sostuvo, por el contrario, que la muerte de García fue fruto de una traición (89). Sus dardos apuntaban, en este sentido, a aquellos revolucionarios que, en teoría, habían dilapidado el dinero entregado por el Rey de los Campos para la causa independentista, aunque no debe olvidarse la idea de la venganza por el secuestro, todavía reciente, del hermano del diputado autonomista Antonio Fernández de Castro, pues Alfredo Ponce Martorell estaba empleado, al parecer en uno de los ingenios que los Fernandez de Castro poseían en la zona de Jaruco.

La tesis de la traición parece apuntar, en un todo coherente, al trío formado por Pedro Betancourt y los prácticos Fidel Fundora -miembro, asimismo, de otra saga de insumisos-, y Alfredo Ponce Martell. Sobre los tres planearía, además, como un personaje contradictorio por sus vinculaciones al aparato colonial y por sus inmunerables defectos e indecisiones, el general Julio Sanguily, gran responsable del fracaso de la insurrección occidental, como se ha dicho. Por si fuera poco, según el coronel José Dolores Amieva, en los momentos iniciales del alzamiento se había producido una reunión entre Fundora y Betancourt:

Inmediatamente mandé a Manuel Gutiérrez avisar a Betancourt que se hallaba en su casa Río esquina a Ayuntamiento con Fidel Fundora sin saber nada de lo que ocurría y yo avisé a todos los del grupo y fui a ver a Tomás López para que él avisara a Emilio Domínguez y demás, le avisé a Julián Gallo, Manuel Pinto y así a todos se les fue avisando lo que ocurría y así se evitó también ser presos, acordando esperar a que se formalizara el movimiento y de no irnos a Cayo Hueso para de allí venir en las Expediciones, por la noche se supo la desgraciada noticia de la muerte de Manuel García hombre patriota práctico y valiente que hubiese sido el salvador del movimiento de Matanzas... (90).

(89) M. Poumier, [80], págs. 216-218.

(90) «Memorias del Coronel José Dolores Amieva», manuscrito. AHPM. Gobierno Provincial, Orden Público, Guerra de Independencia, Leg. 12, n.o 261, fol. 14. 
Otros testimonios contemporáneos parecen reforzar la tesis que venimos comentando. López Coloma, por ejemplo, escribió desde "La Cabaña» a Juan Gualberto Gómez, el 2 de junio de 1895, "parece ser que Betancourt había admitido a última hora para tomar parte en el movimiento revolucionario a Manuel García y que en una entrevista con él había quedado en mandarle a Fidel Fundora y Alfredo Ponce, que trabajaban con él y los Acevedo. Los mandó en la mañana del domingo como a las 10». Y, luego, añade: «Betancourt mandó a Pedro Acevedo al paso de San Juan a esperar a Manuel García, a un grupo de Santa Ana y a un bote con gente de Matanzas: El grupo de Santa Ana y el bote vinieron; pero Manuel García y su gente no aparecían. Como a las 11 ó 12 de la noche oyó decir Pedro Acevedo a unos caminantes que habían matado a Manuel García, no obstante siguió esperando; pero como a las tres de la madrugada en vista de que Manuel García no aparecía les dijo a la gente que se retiraran» (91).

Por su lado, el propio Pedro Betancourt expuso a Juan Gualberto Gómez su papel en relación con el fracasado Grito de Ibarra. En carta fechada en Wilmington (Delaware), el 8 de septiembre de 1895 , se refirió a los hechos acaecidos entre el 21 y el 28 de febrero, «época en que salí para España a bordo del Montevideo». Según confiesa Betancourt, "para dar cumplimiento a una importantísima comisión, que recibí a última hora del Comité Central en La Habana y de la cual por lo trascendental que era hará memoria, me vi obligado a estar ausente de Mantanzas el día 22 y todo el 23, hora en que puse a usted un telegrama, a la dirección por nosotros concertada, dándole cuenta del resultado de mis gestiones, sólo en aquella parte que por el momento le era a usted conveniente o necesario conocer...» Y concreta, finalmente, el general matancero:

De donde se supone que a aquella hora yo lo creía a usted aún en La Habana; pues no tenía noticia de su llegada a Ibarra, cuyo aviso recibí tres horas después, a las once de la noche por Bonifacío Gómez.

(91) Carta de López Coloma a J. G. Gómez, La Cabaña, 2 de junio de 1895 (reproducida en J. Fernández FERnÁNDEZ y N. LópeZ NovegIL: BandolerosInsurrectos, obra mecanografiada, folios 406-408).

R. I., 1996, n. $^{\circ} 207$ 
Por él supe que en Ibarra ustedes me esperaban y a aquel lugar me hubiera marchado inmediatamente si mis deberes y compromisos como Presidente del Comité no me hubieran forzosamente retenido en la ciudad, para cumplir la misión que por la Junta se me había conferido: en primer lugar, la importante comisión que venía a desempeñar, traía aparejados ciertos arreglos absolutamente necesarios, que indispensable e ineludiblemente tenía que ajustar aquella noche, entre ellos se contaba el envío de los prácticos a determinado lugar, cuyas personas se me habían señalado concretamente y a quienes tenía que encontrar y poner en condiciones de desempeñar su cometido... (92).

A su vez Martín Marrero enlazó la incorporación del práctico Fundora, designado por el general Betancourt, con los últimos momentos de la vida de Manuel García Ponce (93):

En estas condiciones Manuel García emprendió su marcha en pie de guerra [...], salió sin novedad [...] continuando su marcha, poco después el práctico que lo guiaba le dijo a Manuel que se adelantara un poco con él, porque tenía que darle órdenes reservadas del Doctor Betancourt, así lo hizo éste, se adelantaron los dos a poca distancia de la vanguardia y en estas condiciones sonaron dos tiros, todos corrieron hacia allí recogiendo a Manuel García moribundo, falleciendo en esos momentos. El práctico desapareció sin que fuera posible darle alcance.

Y, también, el general Loynaz del Castillo sostiene, sin ambages, la tesis de la traición (94):

Horas antes, víctima de la traición de uno de sus compañeros, había caído asesinado en campo cercano a Ceiba Mocha el temerario Manuel García cuando al frente de un escuadrón rápidamente reclutado y con la bandera de Cuba al frente marchaba a proteger la sublevación -malograda por

(92) Carta de Pedro Betancourt a Juan G. Gómez, Wilmington, 8 de septiembre de 1895 (reproducida en J. FERNÁNDEZ FERNÁNDEZ y N. LóPEZ NoveGIL, idem, pág. 409-410).

(93) «Diario de Operaciones...», ANC.

(94) E. LOYNAZ [81], pág. 117. 
esta causa- del Doctor Pedro Betancourt y su grupo que regresaron el siguiente día a Matanzas.

Recientemente, además, el periodista Reynaldo González Villalonga, basándose en los testimonios de Figueroa y de Chema Bolaños, otro testigo de la muerte de Manuel García Ponce, insistió en el asunto, al plantear que la misión de los prácticos era borrar toda huella relativa al uso indebido del dinero donado por el bandolero para la empresa emancipadora. Cuando los testimoniantes llegaron al lugar donde García se encontraba moribundo, los dos «infiltrados» habían desaparecido, "ya no estaban allí. Faltaban dos carteras de campaña, una de las cuales contenía cierta suma de dinero, y la otra los nombramientos de comandante y coronel, ganados por el Rey..., así como los comprobantes de las crecidas sumas de dinero entregadas a varios jefes revolucionarios de La Habana y Matanzas...» (95).

Al día siguiente de los hechos, en fin, el Juez municipal de Ceiba Mocha, como encargado del registro civil, autorizó el enterramiento del cadáver de un desconocido, un «individuo de raza blanca, estatura regular, más bien alto, envuelto en carnes, como de cuarenta años de edad, lleva bigote poco poblado, con algunas canas al lado derecho, recién afeitado y cortado el pelo...», que había sido "hallado por el teniente de la Guardia Civil don Luis Rabadán en el camino que va de la tienda del Seborucal al Real de Matanzas» (96).

(95) R. GonZÁlez Villalonga: «Sobre el tapete el asesinato de Manuel García», Girón, Matanzas, 24 de febrero de 1991, pág. 5.

(96) Registro Civil de Ceiba Mocha, tomo VII, fol. 581, Defunciones. Gentileza de Francisco Lancho. Luis Rabadán Terrón o Terro figura, en 1891, como capitán de Infantería, aunque reaparece aquí como teniente de la Guardia Civil, lo que puede inducir a error. Su expediente personal, en el Archivo General Militar de Segovia (Sección 1. ${ }^{\mathrm{a}}$ Leg. R-4), arroja poca información, pues finaliza a comienzos de la década de 1880 , si bien deja ver que el interesado había pertenecido tanto a la Guardia Civil, como, en 1876, a la V Guerrilla volante de Sancti Spíritus, con la graduación de Alférez movilizado, año en que, también, solicitó su reingreso en el citado Instituto. Es lógico, pues, que de acuerdo con los intereses del Ejército de Ultramar y los suyos propios, Luis Rabadán cambiase de filiación en diferentes momentos. En 1881, además, y como teniente de la Guardía Civil, solicitó licencia para Matanzas por asuntos propios, la que le fue concedida. Se intuye que era un profundo conocedor de la zona.

R. I., 1996, n. 207 
Dos días después se recibió, empero, un oficio del comandante instructor, en el que éste comunicaba la identificación del cadáver del antiguo bandolero "Manuel García y Ponce de León..., hijo de doña Isabel Ponce de León, fallecida, natural de Canarias, bautizado en Alfonso Doce, de unos cuarenta y siete años de edad y casado con doña Rosario Vázquez, no dejando sucesión", y así se hizo constar en el correspondiente libro del registro civil de la localidad» (97). En efecto, el cadáver fue exhumado y reconocido, el 27 de febrero, por Julián Osma y otras personas. La Discusión publicó un comentario no exento de cierta nostalgia (98):

Allí mismo, junto a la tapia, quedó para siempre sepultado el célebre bandido.

A la entrada, junto a la tapia de la derecha y casi al centro de ella, en el Cementerio de Ceiba Mocha, reposa el que a tantos quitó el reposo.

El Cementerio de Ceiba Mocha, sin pinos ni flores, y siempre limpio, será recordado por todos los viajeros que frecuentan la línea de Matanzas, como un sitio notable, no sólo por lo pintoresco de su situación, sí que también por guardar los restos de uno de los más temibles y audace bandoleros de Cuba.

Al final, como hemos visto, el interrogante inicial se sostiene: ¿Quién mató a Manuel García? R. Schwartz afirma que sea cual fuere el testimonio más cierto sobre su muerte, «su partida terminó en ese camino polvoriento. Meses más tarde Gallo Sosa mató a Vicente García en una disputa por la jefatura del grupo. La incertidumbre en torno a las circunstancias que rodearon el final de García crearon una desconfianza generalizada entre los revolucionarios hacia los seguidores de Manuel, que se mantuvieron alejados de la lucha durante un tiempo. Luego volverían al ejército cada uno por su lado. Gallo Sosa, tal vez el último de la partida original, luchó con los insurrectos en Pinar del Río al año siguiente. Parece ser que nadie recogió

(97) Registro Civil de Ceiba Mocha, tomo VII, fol. 584, Defunciones. Gentileza de Francisco Lancho.

(98) V. La Discusión, La Habana, 27 de febrero de 1895. 
los 10.000 pesos de recompensa ofrecidos por la cabeza de Manuel García» (99).

Estas palabras, matizables en más de un aspecto, son, también, una comprensible declaración de impotencia para llegar al fondo de la verdad. Como escribió el antropólogo Jan Vansina, "todo historiador que trate con fuentes debe interpretarlas. No hay conocimiento histórico ilimitado, no podría haberlo, y en la mayoría de los casos hay más de una interpretación posible. Finalmente, pues, el historiador añade algo suyo a estas fuentes, su olfato particular, que es una cualidad más propia del arte que de la ciencia... La historia sólo es un cálculo de probabilidades» (100).

Así, pues, siguiendo los consejos de Vansina, sería conveniente repensar algunas cuestiones. Julio Sanguily, como vimos al principio, tuvo multitud de oportunidades para entregar a Manuel García y nunca lo hizo, antes al contrario, se convirtió en su valedor. Podría argüirse, en este sentido, que el general insurrecto prefería costearse su elevado tren de vida explotando a los dos bandos, esto es, cobrando su sueldo de confidente y aprovechándose, al mismo tiempo, de las extorsiones del Rey de los Campos. Mas, ino le hubiera sido más fácil convertirse en una especie de Marcos García y, tras cobrar una suculenta recompensa, asegurar para siempre su vida de boato y de tahúr?

En segundo lugar, respecto a Pedro Betancourt, es posible que por propia iniciativa -io por órdenes de Sanguily?- quisiera eliminar a un personaje molesto que podría complicarle la existencia -celos profesionales, liderazgo, encubrimiento del mal uso de las sumas de dinero entregadas para la empresa independentista, etcétera-, pero que, en cualquier caso, iba a convertirse en una insustituible fuerza de apoyo para la acción militar en Occidente, por lo que su muerte hubiera constituido, como de hecho sucedió, un grave inconveniente para la consolidación del Grito de Ibarra. La contradicción, pues, es evidente.

(99) R. Schwartz: Lawless Liberators. Political Banditry and Cuban Independence, Duke University Press, Durham, 1989, pág. 234.

(100) J. VANSINA, La tradición oral. Ed. Labor, Barcelona, 1968, pág. 196:

R. I., 1996, n.o 207 
Los dos prácticos, Fidel Fundora y Alfredo Ponce, enviados por Betancourt, se supone que formaban parte de la estrategia conspirativa, es decir, que tenían como misión servir de enlace entre los revolucionarios convencionales y los bandoleros de liberación nacional, pues, con seguridad, Manuel García Ponce contaba con guías suficientemente experimentados para develarle los senderos de Seborucal y Ceiba Mocha hasta «La Ignacia», máxime tratándose de una zona en absoluto desconocida para el propio rebelde; por ello debían ser, en efecto, hombres de confianza del general matancero. Además, en la ya citada carta de Vicente García Ponce del 23 de marzo de 1895, aparte de quedar claro el extremo anterior, también se dice que "entonces Fundora y su compañero siguieron la dirección que llevaban con toda la demás gente, según dicen a ponerse a las órdenes del médico Betancourt», se entiende, pues, que no huyeron apresuradamente.

$Y$, además, recordemos un fragmento del informe del oficial de la Guardia Civil Luis Rabadán, ya mencionado, y que dice así: «...encontrando al poco rato y al lado de un portillo abierto en una cerca de piedra el cadáver de un hombre que por su fisonomía y haberle encontrado varias cápsulas de rifle o revólver comprendí era de la partida y que muy bien puede ser el hombre a quien mandé hacer varios disparos antes de llegar a la expresada tienda por huir al darle el alto por tercera vez». ¿Hubo, pues, al menos un ligero tiroteo con fuerzas de la Guardia Civil?, si esto fue así, se confirman las aseveraciones, al respecto, del propio Fundora.

Pudo suceder, en efecto, que ambos guías se adelantaran con Manuel García Ponce para comunicarle alguna información o petición confidencial -0 , simplemente, como vanguardia, pues eran los "prácticos», esto es, los que mostraban el camino-, y que, en aquel instante, un encuentro incidental con la Guardia Civil acabase con la vida del temido bandolero. Es posible, incluso, que en el nerviosismo de la situación, un disparo errático del imberbe Alfredo Ponce acabase con la vida del mítico insumiso, ¿cómo contar entonces, toda la verdad?

El olfato o, tal vez, el instinto del que escribe Vansina, el arte al fin, nos dice que la tesis de la traición, aunque no puede descartarse, es demasiado evidente, demasiado clara, para tratarse de una intriga de tamaña envergadura, y que en absoluto 
resiste una comparación, por ejemplo, con el retorcimiento y la finura "conspirativa", si puede definirse así, que condujo a las muertes de tantos bandoleros de armas tomar en la misma provincia de Matanzas por aquellos años, sobre todo bajo el mandato de Polavieja (101). Es como si, a través del tiempo, alguien nos quisiera hacer creer que, efectivamente, la muerte de Manuel García Ponce sólo pudo provenir de una traición y que esa traición sólo pudieron maquinarla y ejecutarla los propios cubanos. ¿Por qué?, pues, simplemente, porque ese es el destino de todos los grandes bandoleros. Su muerte, como su vida, es necesariamente legendaria, son casi inmortales por sus especiales características y sólo caen cuando son traicionados por algún Judas desde dentro de la propia partida.

El mayor misterio de la muerte de Manuel García Ponce fue, pues, el hecho mismo de su fallecimiento. Alguien que había resistido durante tanto tiempo a tantos enemigos no podía morir de forma casi irrelevante, por ello con el paso de los años, surgieron acusadores y acusados, testigos que, al fin, se decidieron a hablar tras décadas de sepulcral silencio. Es una forma de participar de la victoria o de la desgracia, pero siempre una cuestión de prestigio y de honor históricos. Manuel García Ponce descansó, al fin en paz, en el pequeño cementerio de Ceiba Mocha, y su contribución a la gesta emancipadora fue, sin duda, su principal victoria, aunque el destino no le permitiera lucir, en plena "rectitud" revolucionaria, las estrellas que se había ganado con su propio esfuerzo en la manigua, desde muchos años antes de que Cuba se levantara, con posibilidades reales de éxito, contra la España arcaica e intransigente de finales del siglo xIx.

Pero, asimismo, la hoja de servicios del ya coronel Guillermo Tort y Gil, nos aporta nueva información sobre el asunto (102):

En 29 de febrero [de 1895] como jefe de la provincia de La Habana que venía desempeñando desde 19 de julio de 1890, estuvo al tanto desde diciembre de 1894 del movimiento insurreccional que venía fraguándose y los proyectos que acariciaba el bandido Manuel García, quien por poderes con-

(101) Cfr. M. DE PaZ-Sánchez, [1], t. I, cap. VI.

(102) AGM. Sección 1.a, División 1. a, Legajo T-1055.

R. I., 1996, n.o 207 
fiados por la junta revolucionaria en el extranjero, debía levantar partida de 800 hombres para dividida en pequeñas de a 100, en día determinado, asolar la provincia de La Habana dando fuego a los poblados más aislados y a toda la zona azucarera más productiva, en combinación con otra partidas que habían de hacer lo propio en la de Matanzas.

Precisado ya el día 24 de febrero que supo desde el 19, después de conferenciar con las autoridades y dado instrucciones al Jefe de la Guardia Civil de Matanzas, con conocimiento de que el movimiento se hacía por el término de Aguacate, tomó sus medidas y montó servicio de emboscadas que dieron por resultado la muerte del referido bandido Manuel García y el fracaso del movimiento combinado en ambas provincias con el médico don Pedro Betancourt y partidas levantadas en Ibarra y Limonar por los cabecillas Antonio López Coloma y el mulato Juan Gualberto Gómez, respectivamente.

Es posible, igualmente, que el coronel Tort tratara de hacer suyo un éxito que no le pertenecía, pero el testimonio asentado en su expediente militar pese a su imprecisión, abona la tesis de que la muerte de Manuel García Ponce y, en general, el fracaso de la rebelión occidental en Cuba no se debió a la traición de los generales insurrectos Julio Sanguily y Pedro Betancourt, sino, más bien, a la debilidad de la propia estructura conspirativa en el occidente cubano, a la existencia, en fin, de múltiples desajustes entre los responsables del alzamiento y a que, en aquellas circunstancias, no todos veían con el optimismo de los emigrados cubanos las posibilidades reales de una insurrección a escasa distancia del centro del poder español en Cuba.

The subject of the failed uprisings of February, 1895 in Cuba's West has been a controversial matter among historians for almonst as long ago as the events themselves. A number of Cuban scholars, as well as the accounts of people who participated in the uprisings, have not helped to the search for the truth. The reasons for this controversy are very much related to the hypothetical relevance of an all-out rebellion emerging just a short distance from Cuba's capital, which would have accelerated the independence movement and changed the conflict's outcome. 
While in a previous work on Cuban banditry I insisted on the critical importance of these uprisings, in this paper I intend to call attention to new data on them, particularly on their most relevant aspect: the role played by the Cuban general Julio Sanguily y Garritte. He has been blamed for the failure of the western revolt, on account of the death of rebel officer-and former social bandit-Manuel García Ponce.

R. I., 1996, n.o 207 